\title{
Perspectivas de proteção ao meio ambiente através de câmaras municipais de mediação e conciliação
}

\author{
Carina Deolinda da Silva Lopes \\ Francieli Bianquin Grigoletto Papalia
}

\begin{abstract}
Resumo: A pesquisa pretende analisar possibilidades para que possam ser criadas e mantidas Câmaras de Mediação e Conciliação para o desenvolvimento e proteção de direitos, tanto da administração pública quanto dos cidadãos, conforme determina o artigo 174 do Código de Processo Civil de 2015. Para a realização da presente pesquisa, utilizarse-á do método teórico bibliográfico, uma vez que se delimitou o estudo a partir do referencial legal, teórico, tais como Jurgen Habermas e Luiz Alberto Warat, para que, com base nestes, seja possível desenvolver uma resposta às possibilidades de aplicação e concretização da proteção, também do meio ambiente, através de mediações advindas entre o âmbito público municipal e a sociedade local. Dessa forma, o estudo buscou analisar, de forma teórica e através do cenário processual, que, dentro da administração pública municipal, existe a possibilidade de concretização e efetividade da utilização de câmaras de medicação e conciliação na perspectiva de garantir proteção e desenvolvimento ao meio ambiente local. Para tanto, acredita-se que a mediação é parte importante para a construção de uma cultura de paz também diante dos conflitos ambientais que permeiam o mundo da vida dos conviventes sociais, sendo a comunicação linguística ativa entre os envolvidos uma forma efetiva de produzir um engajamento positivo na busca concreta pela resolução dos conflitos ambientais através das Câmaras de mediação e conciliação municipais, a fim de que seja realizada a concretização desses instrumentos compositivos de resolução de conflitos para a proteção dos direitos ambientais.
\end{abstract}

Palavras-chave: Meio ambiente; Mediação; Conciliação.

Perspectives of environmental protection through municipal media and conciliation chambers

Abstract: The research intends to analyze possibilities where Mediation and Conciliation
Chambers can be created and maintained for the development and protection of rights, both
public administration and citizens, as determined by article 174 of the Code of Civil
Procedure of 2015 . For the accomplishment of this research will use the theoretical
bibliographic method, once the study was delimited from the legal and theoretical
reference, such as Jurgen Habermas and Luiz Alberto Warat, because, based on these, it is
possible to develop a response to the possibilities of application and the protection of the
environment through mediations between the municipal public sphere and local society. In
this way, the study sought to analyze, theoretically and through the procedural scenario,
that within the municipal public administration there is the possibility of achieving and
effective the use of medication and conciliation chambers in order to guarantee protection
and development to the local environment. In order to do so, it is believed that mediation is
an important part of building a culture of peace also in the face of the environmental
conflicts that permeate the world of social life, and active linguistic communication among
those involved is an effective way of producing a positive engagement in the concrete
search for the resolution of environmental conflicts through the municipal mediation and
conciliation chambers, in order to achieve the concretization of these compositional
instruments of conflict resolution for the protection of environmental rights. Keyword: Environment; Mediation; Conciliation.

Perspectivas de protección ambiental a través de cámaras municipales de mediación y de conciliación

Resumen: La investigación pretende analizar las posibilidades donde se puedan crear y mantener las Cámaras de Mediación y Conciliación para el desarrollo y protección de los derechos, tanto de la administración pública como de los ciudadanos, según lo determinado 
por el artículo 174 del Código de Proceso Civil de 2015. Para la realización de esta investigación se utilizará el método bibliográfico teórico, una vez que el estudio esté delimitado a partir del referencial legal y teórico, como Jurgen Habermas y Luiz Alberto Warat, pues, con bases en estos, se puede desarrollar una respuesta a las posibilidades de aplicación y concretización de la protección también del medio ambiente a través de las mediaciones entre la esfera pública municipal y la sociedad local. De esta manera, el estudio buscó analizar, teóricamente y a través del escenario procesal, que dentro de la administración pública municipal existe la posibilidad de lograr y hacer efectivo el uso de cámaras de medicación y conciliación para garantizar la protección y el desarrollo al medio ambiente local. Para ello, se cree que la mediación es una parte importante de la construcción de una cultura de paz también ante los conflictos ambientales que impregnan el mundo de la vida de los convivientes sociales, y la comunicación lingüística activa entre los involucrados es una forma efectiva de generar un compromiso positivo en la búsqueda concreta de la resolución de los conflictos ambientales a través de las cámaras municipales de mediación y conciliación, para lograr la concretización de estos instrumentos compositivos de resolución de conflictos para la protección de los derechos ambientales.

Palabras clave: Medio ambiente; Mediación; Conciliación.

\section{Introdução}

Trabalhar com temas que demandam originalidade é de suma importância para contribuir com o desenvolvimento social, sendo assim, delimitar uma temática que denote tais circunstâncias é bastante difícil, mas acreditando que muito do que foi trazido pelo Código de Processo Civil ainda deve perpassar por estudos e discussões, este artigo pretende observar junto à perspectiva da proteção e desenvolvimento do meio ambiente as relações com o artigo 174, do referido diploma legal.

O artigo supracitado declara que a Administração Pública, tanto no âmbito federal, estadual e também municipal, poderá criar Câmaras de Mediação e Conciliação para a busca alternativa da resolução de alguns conflitos e, assim, elenca-os em três incisos.

Observar-se-á neste estudo a verificação de possibilidades para criação e desenvolvimento de Câmaras de Mediação e Conciliação, buscando o desenvolvimento e proteção de direitos ambientais, tanto da administração pública quanto dos cidadãos, conforme determina o artigo 174 do Código de Processo Civil de 2015.

A pesquisa a ser desenvolvida delimita-se, dessa forma, a estudar a partir do referencial legal e teórico, tais como Jurgen Habermas e Luiz Alberto Warat, formas para que seja possível desenvolver uma resposta às possibilidades de aplicação e concretização da proteção do meio ambiente através de mediações advindas entre o âmbito público municipal e a sociedade local.

Importante na delimitação do tema é contemplar a explicação de que o diploma legal dá início aos questionamentos desse trabalho, sendo demandadas duas perspectivas de resolução alternativa de conflitos, a mediação e a conciliação. 
Neste passo, a fim de delimitar e organizar os estudos, será dado enfoque para a mediação dos conflitos, observando-se a conciliação, porém dando ênfase para a mediação, uma vez que demanda maior atenção, haja vista a existência de todo um modelo e estrutura de formalização e execução para a chegada das partes a uma composição amigável de seu problema.

Dessa forma, baseado na metodologia teórica bibliográfica, o estudo pauta-se em, através do artigo 174 do Código de Processo Civil, observar, dentro da administração pública municipal, a possibilidade de concretização e efetividade da utilização de câmaras de medicação e conciliação na perspectiva de garantir proteção e desenvolvimento ao meio ambiente local.

\section{Fundamentação Teórica}

\subsection{O meio ambiente e a possibilidade de criação de Câmaras de Mediação e Conciliação para resolução de conflitos administrativos municipais}

A ideia de observação da problemática que envolve a possibilidade de criação de Câmaras de Mediação e Conciliação para a resolução de conflitos ambientais tende a favorecer e buscar interligar pontos comuns entre a questão do direito de todo ser humano possuir um meio ambiente equilibrado e garantir essa proteção, bem como analisar a viabilidade da concretização desse direito e de suas garantias através da utilização de Câmaras municipais de Mediação e Conciliação.

Atenta-se para a possibilidade de concretização da proteção do meio ambiente favorecendo o campo local, sendo que o Código de Processo Civil elenca também a possibilidade de criação das câmaras municipais, bem como observa uma possível contribuição, inclusive, para a desnecessidade de judicialização de todos os conflitos ambientais locais, contribuindo para o desafogamento dos processos judiciais.

Entre as tantas disposições legais, a Constituição Federal em seu artigo $225^{1}$ legisla no sentido de que todos os cidadãos têm direito ao meio ambiente ecologicamente equilibrado,

\footnotetext{
1 Art. 225. Todos têm direito ao meio ambiente ecologicamente equilibrado, bem de uso comum do povo e essencial à sadia qualidade de vida, impondo-se ao poder público e à coletividade o dever de defendê-lo e preservá-lo para as presentes e futuras gerações. $\$ 1^{\circ}$ Para assegurar a efetividade desse direito, incumbe ao poder público:

I - preservar e restaurar os processos ecológicos essenciais e prover o manejo ecológico das espécies e ecossistemas;

II - preservar a diversidade e a integridade do patrimônio genético do País e fiscalizar as entidades dedicadas à pesquisa e manipulação de material genético;
} 
bem de uso comum, sendo essencial à sadia qualidade de vida, impondo-se ao poder público e à coletividade o dever de defendê-lo e preservá-lo para presentes e futuras gerações.

Em seus incisos, o referido artigo já evidencia a necessidade de responsabilização dos indivíduos que derem causa a danos ou exploração em reparação desses, tanto em âmbito administrativo quanto judicial e pena. Nesse viés, que a pesquisa apresentada visa verificar a possibilidade de muitos desses conflitos entre o sujeito que causou o dano ou que possua qualquer demanda ambiental em, através das Câmaras de Mediação e Conciliação, resolver os seus conflitos.

Dito o que determina o texto constitucional, cabe salientar que o Código de Processo Civil de 2015 no artigo $3^{\circ}$ e seus respectivos parágrafos, refere a possibilidade de solução consensual entre as partes através da realização de conciliação, mediação ou outro método de composição, a fim de satisfazer de forma justa e efetiva a pretensão das partes. A fundamental importância é a aplicabilidade dos princípios da boa-fé, cooperação e razoável duração do processo, que deverá ser realizada pelas partes, ou seja, a busca de uma solução mais rápida para o problema, que qual traz o conflito entre as partes.

No nosso ordenamento jurídico, a mediação vem ganhando espaço desde a década de noventa, estando, agora, normatizada no atual diploma Processual Civil, o qual prevê, no artigo $3^{0^{2}}$ e seus parágrafos, a questão da mediação e da conciliação como de suma importância, sendo que o artigo 174 do mesmo ordenamento jurídico traz a mediação e a conciliação com enfoque tanto em âmbito nacional, estadual e também municipal, conforme se observa:

III - definir, em todas as unidades da Federação, espaços territoriais e seus componentes a serem especialmente protegidos, sendo a alteração e a supressão permitidas somente através de lei, vedada qualquer utilização que comprometa a integridade dos atributos que justifiquem sua proteção;

IV - exigir, na forma da lei, para instalação de obra ou atividade potencialmente causadora de significativa degradação do meio ambiente, estudo prévio de impacto ambiental, a que se dará publicidade;

V - controlar a produção, a comercialização e o emprego de técnicas, métodos e substâncias que comportem risco para a vida, a qualidade de vida e o meio ambiente;

VI - promover a educação ambiental em todos os níveis de ensino e a conscientização pública para a preservação do meio ambiente;

VII - proteger a fauna e a flora, vedadas, na forma da lei, as práticas que coloquem em risco sua função ecológica, provoquem a extinção de espécies ou submetam os animais a crueldade.

$\S 2^{\circ}$ Aquele que explorar recursos minerais fica obrigado a recuperar o meio ambiente degradado, de acordo com solução técnica exigida pelo órgão público competente, na forma da lei.

$\S 3^{\circ}$ As condutas e atividades consideradas lesivas ao meio ambiente sujeitarão os infratores, pessoas físicas ou jurídicas, a sanções penais e administrativas, independentemente da obrigação de reparar os danos causados.

${ }^{2}$ Art. 3o Não se excluirá da apreciação jurisdicional ameaça ou lesão a direito.

$\S 1$ ó Eermitida a arbitragem, na forma da lei.

§ 20 O Estado promoverá, sempre que possível, a solução consensual dos conflitos.

§ 3o A conciliação, a mediação e outros métodos de solução consensual de conflitos deverão ser estimulados por juízes, advogados, defensores públicos e membros do Ministério Público, inclusive no curso do processo judicial. 
Art. 174. A União, os Estados, o Distrito Federal e os Municípios criarão câmaras de mediação e conciliação, com atribuições relacionadas à solução consensual de conflitos no âmbito administrativo, tais como:

I - dirimir conflitos envolvendo órgãos e entidades da administração pública;

II - avaliar a admissibilidade dos pedidos de resolução de conflitos, por meio de conciliação, no âmbito da administração pública;

III - promover, quando couber, a celebração de termo de ajustamento de conduta.

Diante da análise dos artigos supracitados, o Código de Processo Civil de 2015 tem a expectativa de que muitos dos conflitos envolvendo a administração pública municipal possam ser dirimidos em âmbito local, sem a necessidade de judicialização, possibilitando, assim, a redução da quantidade de processos que tramitam por muitos e muitos anos no Poder Judiciário sem uma resposta efetiva. Expresso em outros termos, o novo Código de Processo Civil tem uma preocupação excessiva na implantação da composição, que não deixa de ser um método primitivo de resolução de conflitos entre pessoas, desde as épocas tribais. Nesse sentido:

\begin{abstract}
O interesse pela mediação e a conciliação e a importância de que as vias consensuais se revestem na sociedade contemporânea levaram ao renascer do instituto, em toda parte. Se é certo que, durante um longo período, a hetero-composição e a autocomposição foram considerados instrumentos próprios das sociedades primitivas e tribais, enquanto o processo jurisdicional representava insuperável conquista da civilização, ressurge hoje o interesse pelas vias alternativas à o processo, capazes de evitá-lo ou encurtá-lo, conquanto não o excluam necessariamente (PELLEGRINI, 2008, p. 1).
\end{abstract}

Assim, a nova lei delimita bem o papel da conciliação e da mediação, já que os dois institutos não se confundem. Na conciliação, é imposta a um terceiro imparcial a missão de tentar aproximar os interesses de ambas as partes, orientando-as na formação de um acordo.

A mediação é um processo que oferece àqueles que estão vivenciando um conflito, geralmente decorrente de alguma relação continuada, a oportunidade e o ambiente adequados para encontrarem, juntos, uma solução para o problema, através da significação dos sujeitos envolvidos e reconstrução simbólica do conflito. Segundo Luis Alberto Warat:

[...] uma forma ecológica de resolução dos conflitos sociais e jurídicos; uma forma na qual o intuito de satisfação do desejo substitui a aplicação coercitiva e terceirizada de uma sanção legal. A mediação é uma forma alternativa (com o outro) de resolução de conflitos jurídicos, sem que exista a preocupação de dividir a justiça ou de ajustar o acordo às disposições do direito positivo. (WARAT, 1998, p. 5).

A professora Ada Pellegrini contempla pensamento importante sobre a questão funcional da mediação:

Releva, assim, o 'fundamento social' das vias conciliativas, consistente na sua função de pacificação social. Esta, via de regra, não é alcançada pela sentença, que se limita a ditar autoritariamente a regra para o caso concreto, e que, na grande 
maioria dos casos, não é aceita de bom grado pelo vencido - o qual contra ela costuma insurgir-se com todos os meios na execução -, e que, de qualquer modo, se limita a solucionar a parcela de lide levada a juízo, sem possibilidade de pacificar a lide sociológica, em geral mais ampla, da qual aquela emergiu, como simples ponta do iceberg. Por isso mesmo, foi salientado que a justiça tradicional se volta para o passado, enquanto a justiça informal se dirige ao futuro. A primeira julga e sentencia; a segunda compõe, concilia, previne situações de tensões e rupturas, exatamente onde a coexistência é um relevante elemento valorativo. (PELLEGRINI, 2008, p. 25).

Pelo novo Código de Processo Civil, a conciliação, a mediação e a arbitragem deverão ser estimuladas por juízes, advogados, defensores públicos e membros do Ministério Público, inclusive no curso do processo judicial.

Assim, vislumbra-se que a intenção da nova lei é a solução dos litígios através do acordo entre as partes, independente da forma que será realizada, ou seja, se conciliação, se mediação. Mas, no caso de não realizado acordo entre as partes, o processo seguirá o seu curso normal, com a citação do requerido.

A Mediação é um procedimento em patamar de grande discussão atualmente, tendo em vista os estudos que estão sendo efetuados e a extensão dos cursos na área, tendo em vista a propagação de uma cultura de paz e do entendimento desse conceito como uma alternativa de resolução de conflitos.

O Conselho Nacional de Justiça busca trabalhar com o conceito de mediação da seguinte forma:

\begin{abstract}
A Mediação é uma forma de solução de conflitos na qual uma terceira pessoa, neutra e imparcial, facilita o diálogo entre as partes, para que elas construam, com autonomia e solidariedade, a melhor solução para o problema. Em regra, é utilizada em conflitos multidimensionais, ou complexos. A Mediação é um procedimento estruturado, não tem um prazo definido, e pode terminar ou não em acordo, pois as partes têm autonomia para buscar soluções que compatibilizem seus interesses e necessidades (CNJ, 2015).
\end{abstract}

Neste sentido, a mediação é um procedimento para buscar a solução dos conflitos, por meio voluntário, onde as partes, através do diálogo, entendimento e solidariedade, tenham condições de tratar o problema e chegarem a um acordo, porém este não chega a ser obrigatório, para que haja o registro do ocorrido e tratado em Ata.

O professor e advogado José Rogério Tucci (2017) define a mediação de forma completa ao explanar que:

A mediação constitui um mecanismo de solução de conflitos na qual uma terceira pessoa, neutra e imparcial, fomenta o diálogo entre as partes, para que elas próprias construam, com autonomia e solidariedade, a melhor solução para o problema. Geralmente, é ela recomendada para litígios mais complexos, que envolvam várias questões entre as partes. A conciliação, por sua vez, é um meio empregado em conflitos mais singelos e menos abrangentes, no qual o terceiro normalmente se porta de foram mais ativa, embora sempre neutra e imparcial. Normalmente, é um 
procedimento consensual mais breve, que trabalha alvitrando efetiva harmonia entre os litigantes. Tenha-se presente que essas duas técnicas de persuasão são pautadas pelos princípios da informalidade, celeridade, simplicidade, economia, oralidade e flexibilização procedimental.

Costuma-se afirmar entre os profissionais que trabalham com essa forma de solução alternativa de conflitos que o importante é "plantar a semente do diálogo e do entendimento", de fato, quando se consegue ao menos fazer com que as partes iniciem, através das conversas, um pensar diferente sobre o conflito, evidenciando-se um ganho dentro do plano da mediação.

Dentro dessa perspectiva de conciliação e mediação, de conversação e de ganhaganha, o meio ambiente como um bem comum pode ser objeto de atenção também pelo procedimento da resolução de alternativas de conflitos, favorecendo o entendimento e o diálogo entre a entidade pública e o cidadão em conflito.

Sabe-se que o Poder Judiciário apto pela questão da Jurisdição a fornecer resolução processual aos conflitos sociais já não comporta mais, de forma efetiva e concreta, todos os conflitos que lhe são apresentados, seja face ao tempo ou em razão da falta de colaboração das partes.

É nesse interim que a mediação e a conciliação diretamente envolvidas aos Municípios podem favorecer a resolução de conflitos locais em questões ambientais com maior rapidez e eficiência. Além disso, diante do desenvolvimento do procedimento mediatório poder é desenvolver na sociedade local a conscientização de que o meio ambiente é bem comum e de responsabilidade global.

Sobre a questão ambiental, tem-se que o meio ambiente é tido como macrobem, ou seja, de visão globalizada e integrada, que além de ser incorpóreo e imaterial configura-se como bem de uso comum, sendo assim não se pode dispor da ideia de ambiente ecologicamente equilibrado, uma vez que é patrimônio comum e todos ${ }^{3}$.

José Afonso da Silva (1995, p. 98) qualifica meio ambiente como aquele composto de um complexo de elementos naturais, culturais e artificiais, sendo que o meio ambiente natural abrange o solo, a água, o ar atmosférico, a flora, a fauna, em suma, a biosfera; meio ambiente cultural, por sua vez, é formado pelo patrimônio artístico, histórico, turístico, paisagístico, arqueológico; meio ambiente artificial é integrado pelo espaço urbano construído, tais como edificações, ruas, praças, áreas verdes, equipamentos públicos.

Norberto Bobbio (1992, p. 6) destaca as questões ambientais como direitos de terceira geração, salientando que esses direitos ressaltam manifestação do direito de viver em um

\footnotetext{
${ }^{3}$ BRASIL. Lei n. 6.938, de 31 de agosto de 1981. Dispõe sobre a política nacional do meio ambiente, seus fins e mecanismos de formulação e aplicação, e dá outras providências. Disponível em: http://www.planalto.gov.br/ccivil_03/Leis/L6938.htm. Acesso em: 12. Mar. 2019.
} 
ambiente não-poluído. Salienta ainda o autor que a terceira geração dos direitos propugna por um novo enfoque com base em estratégias de prevenção, adaptação e cooperação internacional entre as nações, cabendo à inteligência humana conduzir o processo histórico em benefício de todos, tendo em vista que os grandes problemas ambientais do mundo atual são globais e exigem soluções universais, das gerações presentes para as gerações futuras.

Neste sentido, Canotilho (1998, p. 325) entende:

\begin{abstract}
Em primeiro lugar, o bem ambiental pode qualificar-se como bem jurídico, se na medida em que o objeto de uma disciplina autônoma distinta, relativamente ao regime jurídico patrimonial dos bens, privados ou públicos, ou da res communis omnium que o constituem. Consequentemente, é necessário que a proteção do meio ambiente tenha na lei ou em outras fontes (p. ex.: comunitárias ou do direito internacional) um título jurídico autônomo. O fundamento da tutela específica e autônoma reconduzir-se-á, logicamente, à necessidade da conservação ou gozo do bem ambiental por parte da coletividade ou do particular uti cives.
\end{abstract}

A necessidade de um direito ao meio ambiente saudável e equilibrado advém da ideia de novos direitos que adentra também na já mencionada dimensões de direitos, estando elencada na terceira dimensão, a respeito disso, o autor Norberto Bobbio ressalta que as demandas e os direitos evoluíram juntamente com a sociedade ${ }^{4}$.

O professor José Alcebíades de Oliveira Júnior (1992, p. 192) destaca como direitos transindividuais, também chamados direitos coletivos ou difusos, aqueles direitos ligados à ecologia, pautados dentro das fases que se passam os direitos em suas evoluções históricas.

Sobre os direitos de amplitude gral e não mais apenas individuais. o autor Antonio Carlos Wolkmer (2002, p. 16) enfatiza:

São os direitos meta-individuais, direitos coletivos e difusos, direitos de solidariedade. A nota caracterizadora desses direitos 'novos' é a de que seu titular não é mais o homem individual (tampouco regulam as relações entre os indivíduos e o Estado), mas agora dizem respeito à proteção de categorias ou grupos de pessoas (família, povo, nação), não se enquadrando nem no público, nem no privado.

Assim, aos direitos transindividuais deve ser dada maior ênfase no sentido de efetividade e concretização; no que tange aos direitos ambientais, toda a nação depende de sua proteção e tem dever de cuidado e preocupação com a efetividade de ações que cumpram, de forma concreta, a sua proteção e equilíbrio, para além das demandas judiciais.

\footnotetext{
${ }^{4} \mathrm{O}$ desenvolvimento e a mudança social estão diretamente vinculados com o nascimento, a ampliação e universalização dos "novos" direitos. Essa multiplicação histórica dos "novos" direitos processou-se, no dizer de Bobbio, por três razões: a) aumentou a "quantidade de bens considerados merecedores de tutela"; b) estendeu-se "a titularidade de alguns direitos típicos a sujeitos diversos do homem"; c) o homem não é mais concebido como ser genérico, abstrato, “(...) mas é visto na especificidade ou na concreticidade de suas diversas maneiras de ser em sociedade, como criança, velho, doente etc.” BOBBIO, Norberto. A era dos direitos. Rio de Janeiro: Campus, 1992, p. 68.
} 
Saber Humano, ISSN 2446-6298, V. 9, n. 14, p. 63-76 Jan./Jun. 2019.

Dessa forma, as exigências cada vez mais crescentes em proteger o meio ambiente e garantir qualidade para todas as gerações de seres vivos culmina em buscar formas efetivas e concretas de conscientização populacional e efetivação das represálias e reparações ambientais daqueles que, por algum motivo, acabaram por causar danos ambientais que serão impactados em todo o mundo de alguma forma.

Observando que independe do local onde deve proteger-se o meio ambiente, evidencia-se que partindo da ideia das Câmaras de Mediação e Conciliação municipais seguindo o artigo 174 do Código de Processo Civil, para resolução de conflitos ambientais, esses poderão ser favorecidos em termos de efetividade e concretização, a fim de proteger o global pelas medidas locais, como já se verifica, inclusive, em ricos julgados do Supremo Tribunal Federal sobre o merecimento de guarida às câmaras de mediação e à questão da inafastabilidade da jurisdição e da reparação integral do dano ambiental ${ }^{5}$.

\footnotetext{
${ }^{5}$ Decisão: Trata-se de agravo contra decisão de inadmissibilidade de recurso extraordinário em face de acórdão do Tribunal de Justiça do Estado de São Paulo, assim ementado: "MEIO AMBIENTE - AÇÃO CIVIL PÚBLICA - INCÊNDIO E DERRAME DE PRODUTO NO SOLO - COMPORTAMENTO IMPRUDENTE DA EMPRESA QUE ALTEROU INDEVIDAMENTE A OCUPAÇÃO DO COMÉRCIO - AUTORIA CARACTERIZADA - AUTUAÇÃO - INDENIZAÇÃO PELOS DANOS AMBIENTAIS DECORRENTES DA POLUIÇÃO ATMOSFÉRICA - CABIMENTO - FORMULA DE CÁLCULO QUE LEVA EM CONTA A CARGA DE EMISSÃO DE GÁS POLUENTE, SEGUNDO A ESTIMATIVA: DIMENSÃO DA ÁREA AFETADA VEZES O TEMPO DE DURAÇÃO DA PROPAGAÇÃO DO FOGO - APURAÇÃO EM SEDE DE LIQUIDAÇÃO DE SENTENÇA - RECURSO PARCIALMENTE PROVIDO" (eDOC 39, p. 10). Opostos embargos de declaração, estes foram rejeitados (eDOC 41, p. 15). No recurso extraordinário, interposto com fundamento no art. 102, III, a, da Constituição Federal, aponta-se violação aos arts. $5^{\circ}$, XXXV; 93, IX; 129, III; e $225, \S 3^{\circ}$, do texto constitucional. Nas razões recursais, alega-se que a Turma julgadora não poderia ter deixado de julgar o pedido de reparação dos danos coletivos, contrariando os princípios da inafastabilidade da jurisdição e da reparação integral do dano ambiental. Colho o seguinte trecho do arrazoado: "Temerário entender que a Câmara de Mediação suprime a necessidade da sentença genérica do art. 95 da Lei 8.078/1990. O v. Acórdão recorrido dá interpretação violadora e nega vigência a todo arcabouço normativo que garante aos lesados plena acessibilidade ao Judiciário, além do reconhecimento judicial de seu direito a plena indenização (...)" (eDOC 46, p. 15). É o relatório. Decido. A irresignação não merece prosperar. $O$ Tribunal de origem, ao examinar a legislação infraconstitucional aplicável à espécie (Lei 6.938/1981) e o conjunto probatório constante dos autos, consignou que a ação civil pública não seria a via adequada para fixar condenação coletiva, e que o dano apurado já estaria suficientemente reparado. Nesse sentido, extrai-se o seguinte trecho do acórdão impugnado: "O Ministério Público insiste na condenação dos réus a indenizar os moradores atingidos. A indenização foi bem indeferida; como anotado no AI n ${ }^{\circ} 994.09 .3515917$ (fls. 1062/1068, vol. 5), instalada a Câmara de Mediação, com a presença do autor na primeira reunião, já em 23-4-2009 a empresa apresentou a avaliação dos danos às residências e as providências a serem tomadas para a reforma dos imóveis da Rua Henrique de Leo e Avenida São Bernardo que tiveram suas casas e bens móveis atingidos e danificados pelo incêndio ocorrido na empresa. 22 famílias integraram a Câmara de Mediação e celebraram acordo com a empresa para recebimento de indenização por danos materiais e morais; integraram a lide como assistentes e juntaram a fls. 1.211/1.371, vol. 6/7 os termos de acordo firmados na referida Câmara e a fls. 1.372/1.383, vol. 7 o relatório descritivo dos serviços que estão sendo realizados nas residências que foram danificadas pelo incêndio, de onde se percebe que a indenização dos prejudicados está sendo solucionada e não merece preocupação neste momento, como se vê a fls. 1844, vol. 9). A assistência da Defensoria Pública e de advogados próprios dispensa a presença do Ministério Público na solução dos problemas individuais. (...) O evento foi grave (uma explosão seguida do derrame de material químico em chamas), mas não deixou vestígios ambientais; a área não está contaminada e o dano ambiental se resume ao período de algumas horas até o controle do fogo pelos bombeiros. A poluição causada é objeto de autuação feita pela CETESB no valor de 10.000 UFESP que, aproximando-se hoje de R $\$ 200.000,00$, implica em sanção apreciável pelo fato ocorrido. Não vejo razão para impor aos réus, ante as peculiaridades do fato, a sanção aplicada e as indenizações a que a empresa está sujeita, mais essa indenização" (eDOC 39, pp. 1819). Assim, verifica-se que a matéria debatida pelo Tribunal de origem restringe-se ao âmbito
} 
Para tanto, de forma muito breve e sintética, verifica-se que a Administração pública municipal tem o dever de aplicar e responsabilizar os infratores ambientais também através da esfera administrativa. Segundo José Afonso da Silva (1995, p. 210), a responsabilidade administrativa "resulta de infração a normas administrativas sujeitando-se o infrator a uma sanção de natureza também administrativa: advertência, multa, interdição de atividade, suspensão de benefícios".

A própria Lei da Política Nacional do Meio Ambiente relaciona a forma de responsabilização dos sujeitos a serem penalizados em seu artigo 14, com a aplicação da penalização pela Administração Pública local, sendo que a presente pesquisa busca analisar e verificar a concretização de acordos e a sua viabilidade através da criação de Câmaras de Mediação e Conciliação.

Neste viés, o autor Jurgen Habermas ${ }^{6}$ (1989, p. 79) apresenta uma interessante visão sobre a utilização entre os sujeitos e seus diálogos a fim de buscarem o entendimento,

infraconstitucional, de modo que a ofensa à Constituição, se existente, seria reflexa ou indireta, o que inviabiliza o processamento do presente recurso. Além disso, divergir do entendimento do Tribunal de origem quanto à integralidade da reparação demandaria o revolvimento do acervo fático-probatório, providência inviável no âmbito do recurso extraordinário. Nesses termos, incide no caso a Súmula 279 do Supremo Tribunal Federal. Nesse sentido, trago precedentes de ambas Turmas deste Tribunal: "DIREITO AMBIENTAL. RESPONSABILIDADE CIVIL POR DANOS AMBIENTAIS. ANÁLISE DE EVENTUAL VIOLAÇÃO DA CONSTITUIÇÃO FEDERAL DEPENDENTE DE REELABORAÇÃO DA ESTRUTURA FÁTICA CONSTANTE DO ACÓRDÃO REGIONAL. EVENTUAL OFENSA REFLEXA NÃO VIABILIZA O MANEJO DO RECURSO EXTRAORDINÁRIO. ART. 102 DA LEI MAIOR. ACÓRDÃO RECORRIDO PUBLICADO EM 31.7.2013" (ARE 869.954 AgR, rel. Min. Rosa Weber, Primeira Turma, DJe 14.5.2015). “AGRAVO REGIMENTAL NO RECURSO EXTRAORDINÁRIO COM AGRAVO. RESPONSABILIDADE CIVIL. DANO AMBIENTAL. REPARAÇÃO. ACÓRDÃO FUNDAMENTADO NA LEGISLAÇÃO INFRACONSTITUCIONAL E NO CONJUNTO PROBATÓRIO. AUSÊNCIA DE OFENSA CONSTITUCIONAL DIRETA. SÚMULA N. 279 DO SUPREMO TRIBUNAL FEDERAL. AGRAVO REGIMENTAL AO QUAL SE NEGA PROVIMENTO” (ARE 888.055 AgR, rel. Min. Cármen Lúcia, Segunda Turma, DJe 28.8.2015). Registro ainda que a controvérsia quanto à negativa de jurisdição teve sua repercussão geral rejeitada por este Tribunal no julgamento do RE-RG 956.302, rel. Min. Edson Fachin, DJe 16.6.2016 (tema 895). Transcrevo sua ementa: "PRINCÍPIO DA INAFASTABILIDADE DA JURISDIÇÃO. ÓBICES PROCESSUAIS INTRANSPONÍVEIS. EXTINÇÃO DO PROCESSO SEM JULGAMENTO DE MÉRITO. QUESTÃO INFRACONSTITUCIONAL. MATÉRIA FÁTICA. AUSÊNCIA DE REPERCUSSÃO GERAL. Não há repercussão geral quando a controvérsia refere-se à alegação de ofensa ao princípio da inafastabilidade de jurisdição, nas hipóteses em que se verificaram óbices intransponíveis à entrega da prestação jurisdicional de mérito". Logo, o recurso não pode ser conhecido, no ponto. Ante o exposto, nego seguimento ao recurso (art. 932, III, do NCPC c/c art. 21, §1º , do RISTF). Publique-se. Brasília, $1^{\circ}$ de agosto de 2018. Ministro Gilmar Mendes Relator Documento assinado digitalmente (ARE 1130529, Relator(a): Min. GILMAR MENDES, julgado em 01/08/2018, publicado em PROCESSO ELETRÔNICO DJe-162 DIVULG 09/08/2018 PUBLIC 10/08/2018).

${ }^{6}$ Para Habermas (1989, p. 79), as interações comunicativas são aquelas em que as pessoas envolvidas põem-se de acordo para coordenar seus planos de ação, o acordo alcançado em cada caso, medindo-se pelo reconhecimento intersubjetivo das pretensões de validez. No caso de processos de entendimento mútuo linguísticos, os atores erguem com seus atos de fala, ao entenderem-se uns com os outros sobre algo, pretensões de validez, mais precisamente, pretensões de verdade, pretensões de correção e pretensões de sinceridade, conforme se refiram a algo no mundo objetivo (enquanto totalidade dos estados de coisas existentes), ou a algo no mundo social comum (enquanto totalidade das relações interpessoais legitimamente reguladas de um grupo social) ou a algo no mundo subjetivo próprio (enquanto totalidade das vivências a que têm acesso privilegiado). Enquanto que, no agir estratégico, um atua sobre o outro para ensejar a continuação desejada de uma interação, 
verdades e mútuas compreensões, podendo, dessa forma, ser verificada, no teor desta pesquisa, a possibilidade da Teoria do Agir comunicativo entre os sujeitos que pode ser aproveitada de forma satisfatória junto ao contexto das Câmaras municipais de Mediação e Conciliação.

A autora Gisele Citadino (2004, p. 108), contextualizando Jurgen Habermas, menciona que "a ação comunicativa, por facilitar o diálogo acaba por trazer uma melhor decisão para os indivíduos e diferentemente do mundo sistêmico, o mundo da ação comunicativa é, o mundo vivido ou o mundo da vida"7.

Partindo da máxima de que a ação comunicativa está inserida na ideia de mundo da vida, ligeiramente parece que tal base teórica possa embasar o estudo, unindo a questão da resolução dos conflitos de âmbito ambiental municipal através das Câmaras de Mediação e Conciliação à teoria do agir comunicativo ${ }^{8}$.

Sendo assim, brevemente, observa-se que é direito de todos, tanto em âmbito local ou global, um meio ambiente equilibrado, sendo que, do aspecto da realidade social atual, apenas as demandas judiciais já não dão conta de contemplar de forma efetiva as necessidades de proteção ao bem comum ambiental, sendo relevante o estudo para a verificação da problemática apresentada.

\section{Considerações finais}

Neste breve esboço sobre a questão da possibilidade de concretização da resolução de conflitos ambientais através da utilização de Câmaras de Mediação e Conciliação, buscou-se também dar ênfase à demonstração de possibilidades de efetividade da ideia apresentada através da análise de conceitos teóricos de Habermas e Warat.

A pesquisa analisou possibilidades a serem utilizadas as Câmaras de Mediação e Conciliação para o desenvolvimento e a proteção de direitos ambientais, tanto da

no agir comunicativo um é motivado racionalmente pelo outro para uma ação e adesão - e isso em virtude do efeito ilocucionário de comprometimento que a oferta de um ato de fala suscita.

${ }^{7}$ Habermas ensina que a integração das democracias contemporâneas tem duplo fundamento: a força resultante de um acordo racionalmente motivado e a ameaça das sanções. Isso significa que a ordem jurídica baseia-se na facticidade e validade: dimensão coercitiva de um direito legalmente instituído e legitimidade resultante de um entendimento conjuntamente negociado, conectando diretamente o direito com a democracia, os direitos humanos com a soberania popular. O direito coercitivo só conserva sua força integradora porque os destinatários individuais das normas jurídicas podem reconhecer a si próprios como autores e destinatários de tais normas (CITTADINO, 2000, pp. 171-173).

${ }^{8} \mathrm{O}$ agir comunicativo pressupõe a utilização da racionalidade recíproca, isto é, a utilização do agir orientado para o entendimento. O contato que os indivíduos possuem com o mundo é mediado linguisticamente, ao passo que a objetividade do mundo - que se supõe ao falar e agir - "está [...] entrelaçada com a intersubjetividade do entendimento sobre algo no mundo" (HABERMAS, 2002, p. 56). 
administração pública quanto dos cidadãos, em relação a conflitos ambientais, conforme determina o artigo 174 do Código de Processo Civil de 2015.

Observou-se que, partindo do conceito de mediação tanto do Conselho Nacional de Justiça, bem como dos referenciais teóricos apresentados, evidencia-se que seja possível desenvolver uma resposta às possibilidades de aplicação e concretização da proteção também do meio ambiente através de mediações advindas entre o âmbito público municipal e a sociedade local.

Dessa forma, o estudo buscou mostrar, através da análise comparativa com o artigo processual citado, observações sobre a administração pública municipal e a possibilidade de concretização e efetividade da utilização de Câmaras de Mediação e Conciliação na perspectiva de garantir proteção e desenvolvimento ao meio ambiente local, inclusive matéria que já chegou a ser decidida em sede de decisão monocrática junto ao Supremo Tribunal Federal, ementa, embora extensa, juntada a este estudo.

O estudo apresentado é um breve levantamento das ideias iniciais a serem perseguidas em futuras pesquisas e publicações, a fim de garantir a continuidade dos estudos e levantamentos sobre as possibilidades de criação e desenvolvimento das câmaras resolutivas de conflitos ambientais em sede municipal.

Inicialmente, passou-se a análise dos parâmetros constitucionais e da legislação processual civil atual em relação ao tema proposto, bem como após a verificação da visão de meio ambiente como direito transindividual e de responsabilidade de todos os seres humanos em sede de proteção e cuidado.

$\mathrm{Na}$ sequência, verificou-se os conceitos das formas de resolução de conflitos, bem como do conceito de mediação para Luiz Alberto Warat, o entendimento da teoria do agir comunicativo de Jurgen Habermas, como bases teóricas que ajudam a fornecer elementos para a concretização da mediação e da conciliação em âmbito local, através do diálogo e do entendimento dos sujeitos.

Em seguida, no artigo apresentado, foi analisado brevemente, dada a permanência do estudo do tema em artigos sequenciais, da efetividade de possibilidade de concretizar as Câmaras municipais de Mediação e Conciliação para dirimir conflitos de situações ambientais.

Assim, acredita-se que a mediação é parte importante para a construção de uma cultura de paz também diante dos conflitos ambientais que permeiam o mundo da vida dos conviventes sociais, sendo que, inicialmente, aponta-se que a comunicação linguística ativa entre os envolvidos possa efetivamente produzir um engajamento positivo na busca concreta 
pela resolução dos conflitos ambientais através das Câmaras de Mediação e Conciliação municipais.

\section{Referências}

BOLZAN DE MORAIS, José Luís e SPENGLER, Fabiana Marion. Mediação e arbitragem: alternativas à jurisdição. 2. ed. Porto Alegre: Livraria do Advogado, 2008.

BRASIL. Constituição (1988). Constituição da República Federativa do Brasil. Organização de Alexandre de Moraes. 16. ed. São Paulo: Atlas, 2000.

BRASIL. Lei n. 6.938, de 31 de agosto de 1981. Dispõe sobre a política nacional do meio ambiente, seus fins e mecanismos de formulação e aplicação, e dá outras providências. Disponível em: http://www.planalto.gov.br/ccivil_03/Leis/L6938.htm. Acesso em: 12. mar. 2019.

CANOTILHO, José Joaquim Gomes. Procedimentos administrativo e defesa do meio ambiente. Revista de Legislação e Jurisprudência, Coimbra, n. 3802, pp. 325-326.

CITTADINO, Gisele. Pluralismo, direito e justiça distributiva. 3. ed., Rio de Janeiro: Editora Lumen Juris, 2004.

COLARES, Elizabeth Fialho. Mediação de conflitos um mecanismo de acesso à justiça. In: SALES, Lília Maia de Morais. A cidadania em debate. Mediação de conflitos. Fortaleza: Fundação Edson Queiroz, 2005.

DINAMARCO, Cândido Rangel. Nova era do processo civil. 3. ed. São Paulo: Malheiros, 2009.

A instrumentalidade do processo. São Paulo: Revista dos Tribunais, 1987.

GORCZEVSKI, Clovis. Jurisdição paraestatal: solução de conflitos com respeito à cidadania e aos direitos humanos na sociedade multicultural. Porto Alegre: Imprensa Livre, 2007.

GOZAÍNI, Osvaldo A. Formas Alternativas para la resolución de conflitos. Buenos Aires: Delpalma, 1995.

HABERMAS, Jürgen. Agir comunicativo e razão destranscendentalizada. Tradução Lucia Aragão. Rio de Janeiro: Tempo Brasileiro, 2002.

Consciência moral e agir comunicativo. Tradução de Guido A. de Almeida. Rio de Janeiro: Tempo Brasileiro, 1989.

JUNGES, José Roque. Ética ambiental. São Leopoldo: Unisinos, 2004.

MORAIS, José Luis Bolzan de; SPENGLER, Fabiana Marion. Mediação e arbitragem: alternativas à jurisdição! 2. ed. rev. ampl. Porto Alegre: Livraria do Advogado Editora, 2008.

MOORE, Christipher W. O processo de Mediação: estratégias práticas para a resolução de conflitos. Tradução de Magda França Lopes. Porto Alegre: ArTmed, 1998. 
OLIVERIA JÚNIOR, José Alcebíades de. O novo em Direito e Política. Porto Alegre: Livraria do Advogado, 1997.

PELLEGRINI GRINOVER, ADA. "Os fundamentos da justiça conciliativa”. Disponível em: https://bdjur.stj.jus.br/jspui/bitstream/2011/21448/fundamentos_justica_conciliativa.pdf. Acesso em: 24. fev. 2019.

RIBEIRO, Regina A.S.F. O Advogado na Conciliação e na Mediação. In: Revista Cientifica Virtual da Escola Superior de Advocacia da OAB - SP. Ano V - No 13. São Paulo. 2013.

SPENGLER, Fabiana Marion. Mediação de Conflitos: da teoria à prática. Porto Alegre: Livraria do Advogado Editora, 2016.

SALES, Lília Maia de Morais. Justiça e Mediação de Conflitos. Belo Horizonte: Del Rey, 2003.

SILVA, José Afonso da. Direito Ambiental Constitucional. São Paulo, Malheiros, 1995.

SIX, Jean-François. Dinâmica da mediação. Trad. Águida Arruda Barbosa, Eliana Riberti Nazareth, Giselle Groeninga. Belo Horizonte: Del Rey, 2001.

TUCCI, José Rogério. Novo Código de Processo Civil introduz a audiência de conciliação ou de mediação. Disponível em: http://www.conjur.com.br/2016-abr-26/paradoxo-corte-cpcintroduz-audiencia-conciliacao-ou-mediacao. Acesso em: jan. 2017.

WARAT, Luis Alberto. Em nome do acordo a mediação no direito. Santa Catarina: AIMED, 1998.

Habitus, 2001.

Luis Alberto. Surfando na pororoca: o oficio do mediador. Florianópolis: 